\title{
IV. Gedankenstrich, Anführungszeichen, Klammern
}

\section{Den Gedankenstrich setzen wir}

1) wenn wir einen Satz abbrechen wollen, um damit einen Gedanken nicht auszusprechen.

Bring mich nicht zum Außersten, sonst -.

2) als Zeichen zur Andeutung einer Pause oder zur Vorbereitung von etwas Unerwartetem:

Da-was war das? - Vor uns tauchte ein schwarzer Fleck auf. werden möcht' ich halt gern, antwortete ich zögernd.

3) um Wörter oder Sätze in einen Satz einzuschalten. Hier war das Blatt - anscheinend absichtlich - abgerissen.

4) um Sätze oder Satzteile deutlich voneinander zu scheiden. Was willst denn? fragte mich nach einer Weile der Meister. - Schneider werden möcht' ich halt gern, antwortete ich zögernd.

\section{Die Anführungszeichen setzen wir}

1) zu Anfang und Schluß einer direkten Rede.

"Gehen wir jetzt", sagte er zu seinen Freunden. - Er antwortete nur kurz: "Keine Zeit.“ - „Eigentlich wollte ich zu Hause bleiben“, überlegte er, „aber das schöne Wetter lockt mich doch hinaus. “

\section{Beachte:}

Die Anführungszeichen werden auch bei direkter Rede häufig weggelassen.

Mutter, sagte der Junge, im Januar werd' ich sechzehn.

2) innerhalb eines Satzes, wenn ein Wort oder eine Wortgruppe als für sich alleinstehend, als genauer Name, Titel oder als Zitat gesprochener oder geschriebener Worte bezeichnet werden soll.

Das Wörtchen „du“. - Goethes „Faust“. - Als du schriebst ,ich komme“, war ich froh.

\section{Zwischen Klammern}

setzen wir Erklärungen, Ubersetzungen und nähere Bestimmungen der vorangehenden oder (seltener) nachfolgenden Wörter: Die Astronomie (Himmels- oder Sternkunde) ist eine interessante Wissenschaft. - Die (übrigens auch heute noch unerledigte) Frage war, ob...

An Stelle der Klammern können oft auch. Gedankenstriche gesetzt werden. Ist ein in Klammern eingeschlossener Satz in einen andern Satz eingeschoben, so erhält er nur ein Satzzeichen, wenn es sich um einen Frage- oder Ausrufesatz handelt (also ein Frage- oder Ausrufezeichen).

Im Konzert (warum warst Du eigentlich nicht dort?) wurden Werke von Haydn und Beethoven aufgeführt. - Am Sonntag machten meine ältere Schwester und ich (meine jüngere Schwester war plötzlich erkrankt) einen Ausflug.

Nur der selbständige in Klammern stehende Satz erhält am Schluß ein Zeichen innerhalb der Klammer.

Für Sätze zwischen Gedankenstrichen gelten die gleichen Regeln. 